\title{
TEMPAT-TEMPAT KERAMAT DI KECAMATAN PANJALU KABUPATEN CIAMIS
}

\author{
THE SACRED PLACES IN PANJALU SUB-DISTRICT OF CIAMIS REGENCY
}

\author{
Aam Masduki \\ Balai Pelestarian Nilai Budaya Bandung \\ Jl. Cinambo No. 136 Ujungberung Bandung \\ e-mail: Masduki.aam@gmail.com
}

Naskah Diterima: 28 Mei $2014 \quad$ Naskah Direvisi: 11 Juli $2014 \quad$ Naskah Disetujui: 18 Agustus 2014

\begin{abstract}
Abstrak
Dewasa ini bangsa Indonesia sedang berada di tengah-tengah kebudayaan yang sedang tumbuh dan berubah sesuai dengan perkembangan ilmu pengetahuan dan teknologi (iptek). Meskipun di tengah arus perkembangan yang sangat pesat dalam segala aspek kehidupan, masih nampak bahwa ada masyarakat yang masih kuat berpegang pada adat kebiasaan dan mentalitas para leluhur mereka tentang kepercayaan sebagai keyakinan dalam hidupnya yang diwujudkan melalui tindakan. Di antaranya pada waktu tertentu pergi atau berkunjung ke tempat-tempat keramat, misalnya makam-makam para leluhur yang dianggap keramat atau tempat-tempat yang dianggap mempunyai tuah dan sebagainya.Tempat-tempat keramat banyak ditemukan di semua daerah di Indonesia. Di tempat-tempat inilah masyarakat pendukung suatu kebudayaan mengekspresikan dirinya secara religius dengan beranekaragaman cara dan laku. Hal tersebut bisa dimengerti karena kepercayaan sebagai salah satu unsur kebudayaan, terdiri atas pola-pola sistematis dari keyakinan anggota masyarakat. Pola-pola tersebut sistematis karena manifestasinya teratur dalam kejadian maupun ekspresinya. Tujuan penelitian ini adalah untuk mengidentifikasi tempat-tempat keramat serta mengungkap fungsi dan maknanya, agar masyarakat terutama generasi muda bisa mengetahui dan memelihara tinggalan leluhur. Penelitian ini bersifat deskriptif dengan menggunakan pendekatan kualitatif yang melihat pada aspek nilai dan konsep berpikir pada masyarakat tersebut, serta penggalian data melalui observasi dan wawancara.
\end{abstract}

Kata kunci: tempat-tempat keramat, Panjalu, Ciamis.

\begin{abstract}
Today the Indonesian nation was in the midst of a culture that is growing and changing in accordance with the development of science and technology. While in the midst of rapid growth in all aspects of life, it appears that there are still people who still hold on to the customs and mentality of their ancestors of faith as belief in life created by the action. Among them at a certain time to go or visiting sacred places, such as the tombs of the ancestors that are considered sacred or places that are considered to have good luck and so on. Sacred places are found in all regions in Indonesia. In places it is public support for a culture to express themselves religiously with various manner and behavior. This is understandable, given the trust as one of the cultural elements, consisting of systematic patterns of society belief-pattern. The patterns are systematic, as a regular in the incidence of manifestations and expressions. The purpose of this study was to identify sacred sites and reveals the function and meaning, so that people, especially younger generations can know and preserve the remains of ancestors. This is a descriptive study using a qualitative approach that looks at the aspects of value and the concept of thinking in the community, as well as extracting data through observation and interviews.
\end{abstract}

Keywords: sacred places, Panjalu, Ciamis. 


\section{A. PEN DAHULUAN}

Keramat dari kata karamah yang berarti mulia, murah dan luhur. Dalam teologi Islam, keramat adalah keistimewaan luar biasa yang dianugerahkan Tuhan kepada seseorang yang dicintai. Keramat dibedakan dengan mujizat yang dianugerahkan kepada para Nabi dan istidraj yang dimiliki oleh orang yang durhaka kepada Tuhan. Keramat sering dikaitkan dengan tokoh yang dipercayai sebagai wali, yaitu orang yang sangat dikasihi Tuhan. Kekeramatan mereka terlihat dalam perbuatan mereka yang luar biasa dan tidak terjangkau oleh akal biasa. Kekeramatan mereka berlangsung terus setelah mereka meninggal. Oleh karena itu dalam masyarakat terdapat kuburan para wali yang diyakini sebagai kuburan keramat dan diziarahi banyak orang untuk memperoleh berkah. Selain itu dalam masyarakat dikenal pula benda keramat, misalnya aneka benda keraton yang dianggap berkhasiat gaib (Ensiklopedi Nasional Indonesia, 1990).

Manusia pada zaman prasejarah telah mengenal akan adanya suatu alam yang tak nampak, yaitu kehidupan yang tak dapat dilihat dengan mata. Alam itu ialah dunia gaib, atau supranatural. Mereka percaya bahwa selain dunia ini, ada lagi dunia lain yang tak dapat dilihat oleh mata. Di dalam dunia gaib terdapat arwah leluhur, hantu, setan, jin, peri, dan lainlain. Kepercayaan akan adanya dunia gaib semacam itu baru mencapai bentuk yang kongkrit pada zaman neolitik dan zaman logam.

Tempat yang dikeramatkan mempunyai latar belakang yang unik, seperti makam yang memiliki latar belakang sejarah orang yang dikeramatkan. Demikian pula halnya yang terjadi di Kabupaten Ciamis, banyak makam dianggap keramat dan dihormati sebagai tokoh suci yang mempunyai pengaruh besar pada umatnya di kemudian hari. Berlatar belakang sejarah dan perjuangannya dalam menegakkan syiar Islam, telah mengokohkan kepercayaan masyarakat, akan tuah dan keramat makamnya. Sesuai dengan pandangan umum masyarakat Indonesia yang menganggap seseorang yang bergelar waliyullah adalah orang yang sangat dekat dengan Tuhan Yang Maha Kuasa. Maka tokoh tersebut beserta pengikutnya yang dimakamkan tidak jauh dari sang tokoh diyakini dapat menjembatani umatnya dengan Tuhan Yang Maha Kuasa.

Tempat-tempat keramat banyak ditemukan di semua daerah di Indonesia. Di tempat-tempat inilah masyarakat pendukung suatu kebudayaan mengekspresikan dirinya secara religius dengan beragam cara dan laku. Hal tersebut bisa dimengerti karena kepercayaan sebagai salah satu unsur kebudayaan, terdiri atas pola-pola sistematis dari keyakinan anggota masyarakat. Pola-pola tersebut sistematis karena manifestasinya teratur dalam kejadian maupun ekspresinya.

Dengan dasar pemikiran tersebut di atas, perlu adanya pengenalan tentang tempat-tempat keramat yang sering dikunjungi masyarakat, apa yang menjadi tujuan mereka mendatangi tempat keramat, dan makna apa yang terkandung dalam tempat keramat tersebut.

Artikel ini bertujuan mendata dan mengidentifikasi dan mengungkap fungsi dan makna simbolis tempat-tempat keramat, serta apa yang menjadi alasan atau motivasi mereka mendatangi tempat keramat.

\section{B. METODE PEN ELITIAN}

Metode yang digunakan untuk penyusunan tentang tempat-tempat keramat di Kecamatan Panjalu Kabupaten Ciamis adalah metode deskriptif dalam bentuk kualitatif, dengan teknik pengumpulan data berupa observasi partisipasi/pengamatan, wawancara mendalam dengan beberapa informan dan pengunjung, serta studi pustaka.

Ruang lingkup penelitian terbagi dua, yakni materi dan wilayah. Yang termasuk ke dalam ruang lingkup materi di antaranya gambaran umum lokasi 
penelitian, bentuk, sifat dan fungsi dari masing-masing tempat keramat. Ruang lingkup wilayah adalah di Kecamatan Panjalu Kabupaten Ciamis Provinsi Jawa Barat.

\section{HASIL DAN BAHASAN}

Panjalu adalah sebuah kota kecil sebagai ibukota dari Kecamatan Panjalu di Kabupaten Ciamis Provinsi Jawa Barat. Kota ini terletak sekitar $100 \mathrm{~km}$ dari ibukota Provinsi Jawa Barat Bandung atau $75 \mathrm{~km}$ dari Cirebon dan sekitar $30 \mathrm{~km}$ dari Ciamis. Wilayahnya termasuk daerah perbukitan atau pegunungan dengan curah hujan rata-rata pertahun $160 \mathrm{~mm}$ dengan suhu udara rata-rata 0,20 derajat celcius.

Pada tahun 2004 kota kecamatan ini telah dideklarasikan sebagai Kota Wisata Budaya Ziarah. Tempat-tempat ziarah itu biasanya dianggap keramat, ada yang terdapat di alam terbuka dan ada yang terdapat di tempat tertutup. Adapun tempat-tempat keramat yang ada di kecamatan Panjalu di antaranya adalah:

\section{Situ Lengkong}

Situ Lengkong atau Situ Panjalu adalah pulau kecil yang masih alami dengan udara yang sejuk, ciri khas dari daerah pegunungan dengan pesona alam yang indah dan jauh dari polusi udara. Situ Lengkong Panjalu terletak di Desa Panjalu, Kecamatan Panjalu, Kabupaten Ciamis, Provinsi Jawa Barat. Situ Lengkong memiliki beragam jenis pohon dan marga satwa yang menjadi objek menarik dari situ tersebut. Danau ini memiliki luas sekitar 64 hektar dan berada pada 700 meter diatas permukaan air laut, kedalaman Situ Lengkong berkisar 4-6 meter.

Setiap hari libur dan hari raya besar Islam, Situ Lengkong dipenuhi oleh berbagai pelancong dan peziarah.Tidak hanya masyarakat Panjalu yang datang ke Situ Lengkong, tetapi dari berbagai kota, bahkan turis dari luar negeri berdatangan untuk berekreasi, berziarah atau ingin mengetahui kebudayaan masyarakat Keca- matan Panjalu, serta menikmati keindahan alam yang masih alami, karena Situ Lengkong Panjalu masih dijadikan tempat keramat. Di sekitar Situ Lengkong Panjalu tersaji makanan khas Kecamatan Panjalu, berbagai jenis kerajinan tangan yang terbuat dari bambu, limbah daur ulang yang terbuat dari plastik, botol dan lainlain. Selain itu, terdapat juga perahu untuk berlayar mengelilingi Situ Lengkong.

Unsur kebudayaan yang masih terjaga menjadikan Situ Lengkong sebagai objek pariwisata serta peziarah yang datang dari berbagai kota di antaranya dari Cilacap, Jakarta, Bandung, Indramayu, Banten, Cirerbon, dan lain-lain. Selain sebagai tempat pariwisata, Situ Lengkong Panjalu juga dijadikan tempat berziarah. Hal yang menarik serta unik dari danau yaitu di tengah-tengah danau tersebut ada daratan yang disebut Nusa Gede atau Nusa Larangan yang luasnya 9,25 Ha. Di dalam Nusa terdapat makam keramat Prabu Sanghyang Hariang Kancana.

Penamaan Nusa Larangan, karena apabila kita berada di daerah Kecamatan Panjalu harus menjaga ucapan serta tingkah laku atau kita harus bersikap sopan jangan sampai ucapan-ucapan yang tidak sopan keluar dari mulut kita. Di sekeliling makam keramat ditumbuhi berbagai jenis pohon besar yang berdiri kokoh.

Para peziarah yang datang ke Nusa Larangan menggunakan perahu yang telah disediakan, di atas perahu mereka melantunkan dzikir serta shalawat, agar mereka terhindar dari hal-hal yang tidak diinginkan. Setelah sampai di Nusa Larangan, mereka masuk dan berdoa kepada Allah SWT dengan niat dan maksud yang diinginkan. Para peziarah diharapkan tidak meminta-minta kepada kuburan serta ingin didoakan oleh orang yang telah meninggal, sebab sama saja dengan menyekutui Allah SWT.

Para peziarah mempercayai bahwa air dari Situ Lengkong dapat menyembuhkan penyakit, karena air situ berasal dari air zamzam yang dibawa oleh Prabu Borosngora dari Tanah Suci Mekah 
pada abad VII. Air tersebut dibawa dengan menggunakan gayung yang berlubang di bagian dasarnya. Gayung tersebut titipan dari ayahnya agar Prabu Borosngora bisa membawa air secanting penuh tanpa menumpahkan isinya. Kenapa air di Situ Lengkong dipercayai sebagai penyembuh penyakit? Hal itu disebabkan di sekitar situ banyak ditumbuhi jenisjenis pohon yang sudah berumur tua serta tanaman obat-obatan yang akarnya masuk ke dalam tanah dan terendam oleh air situ. Air situ pun banyak dimanfaatkan untuk mengairi pesawahan penduduk.

Menurut sejarah Panjalu, Situ Lengkong bukanlah situ alam yang terjadi dengan sendirinya, akan tetapi hasil buatan para leluhur Panjalu. Sejak lebih kurang abad ke-7 Masehi (menurut catatan kebudayaan abad ke-15) di Panjalu telah ada Kerajaan Hindu yang bernama Kerajaan Panjalu. Awal abad ke-7, Raja yang memerintah ialah Prabu Syang Hyang Cakradewa. Raja mempunyai keinginan agar putra mahkota sebagai calon pengganti raja haruslah memiliki terlebih dahulu ilmu paling ampuh dan sempurna, berangkatlah sang mahkota Borosngora. Akhirnya putera mahkota tiba di Tanah Suci Mekah dan di sanalah tujuannya tercapai, yaitu mempelajari dan memperdalam agama Islam.

Setelah cukup lama, maka pulanglah sang putera mahkota ke Negara Panjalu. Ia dibekali air zamzam, pakaian kesultanan serta perlengkapan Pedang dan Cis dengan tugas harus menjadi Raja Islam dan sekaligus mengislamkan rakyatnya. Ia menjadi Raja Panjalu menggantikan ayahnya dengan gelar Syang Hyang Borosngora. Mulai saat itulah Kerajaan Panjalu berubah dari Kerajaan Hindu menjadi Kerajaan Islam. Air zamzam yang dari Mekah ditumpahkan ke sebuah lembah yang bernama Lebah Pasir Jambu. Air di lembah tersebut bertambah banyak dan terbentuklah danau yang sekarang disebut Situ Lengkong.

Pedang, Cis dan Pakaian Kesultanan disimpan di Museum Bumi Alit yang waktu itu merupakan Museum Kerajaan. Istana Kerajaan dipindahkan dari Pasir Dayeuh Luhur ke Nusa Gede Panjalu, sehingga dengan demikian air Situ Lengkong merupakan benteng pertahanan Keraton.

Situ Lengkong atau disebut juga Situ Panjalu merupakan salah satu sisa-sisa peninggalan raja-raja Panjalu yang sekarang masih ada. Benda-benda peninggalan yang masih ada berupa dolmen, lingga, dan batu bekas singgasana/bertapa raja. Bumi Alit, Situ Lengkong dan Upacara Nyangku merupakan salah satu bukti peninggalan sejarah pada waktu agama Islam masuk ke Kerajaan Panjalu, yang merupakan awal terjadinya perkembangan sejarah baru.

Selanjutnya diceritakan pula bahwa Prabu Borosngora memindahkan keraton yang semula terletak di daerah Dayeuh Luhur ke Nusa Gede yang terletak di tengah-tengah Situ Lengkong. Selain keraton, ia juga memindahkan kepatihan yang disebut Hujung Winangun ke sebelah Barat Nusa Gede dan membuat taman serta kebun tempat rekrerasi di Nusa Pakel. Untuk memudahkan komunikasi, dibuatlah dua pintu gerbang untuk memasuki Keraton Nusa Gede. Pintu gerbang yang pertama dibuat dari ukiran dan dijaga oleh Gulang-gulang yang berjenggot yang bernama Apun Obek. Adapun pintu gerbang yang kedua merupakan jembatan yang menghubungkan Nusa Gede dengan daratan, letaknya di sebelah barat yang dikenal dengan nama Cukang Padung (jembatan dari balok-balok kayu). Kini daerah-daerah tersebut dinamakan Dusun Cukang Padung.

Setelah Prabu Borosngora pindah ke Jampang maka kekuasaan Kerajaan Panjalu diserahkan kepada anaknya, Raden Hariang Kuning dan selanjutnya diberikan kepada adiknya yang bernama Raden Hariang Kencana (Embah Panjalu) yang dimakamkan di Situ Lengkong, dan menurunkan raja-raja Panjalu selanjutnya. 


\section{Bumi A lit}

Bumi Alit atau pasucian pada awalnya terletak di Buni Sakti, kemudian dipindahkan ke Desa Panjalu oleh Prabu Sanghyang Borosngora bersama bendabenda pusaka Kerajaan Panjalu. Bentuk Bumi Alit yang lama masih berbentuk tradisional, tempatnya masih berupa tanaman lumut yang dibatasi oleh batubatu besar. Sedangkan di sekelilingnya dipagari oleh tanaman waregu, di tengah tanaman itu berdiri bangunan Bumi Alit yang berukuran besar. Bangunan yang dulu terbuat dari kayu, bambu dan ijuk, bawahnya bertiang tinggi, badan bangunan berdinding bilik sedangkan atapnya dari suhunan ijuk berbentuk pelana. Ujung bungbung menciut berujung runcing dan ditutup dengan papan kayu berukir. Pada sisi bagian barat terdapat pintu kecil yang depannya terdapat tangga kayu yang kuat dari kayu balok tebal.

Pasucian Bumi Alit atau lebih populer disebut Bumi Alit, mulai dibangun sebagai tempat penyimpanan pusaka peninggalan Prabu Sanghyang Borosngora oleh Prabu Rahyang Kancana di Dayeuh Nagasari, Ciomas. Kata-kata bumi alit dalam Bahasa Sunda berarti "rumah kecil" Bumi alit bentuknya bangunan kecil yang berada pada suatu tempat namanya "Pasucian". Nama pasucian sendiri diberikan oleh Raja Panjalu yang bernama Prabu Shangyang Borosngora atau Syeh Haji Dul Imam, raja Panjalu yang memeluk agama Islam. Adapun bendabenda pusaka yang tersimpan di Bumi Alit, antara lain adalah:

1. Pedang, cinderamata dari Baginda Ali r.a, sebagai senjata yang digunakan untuk membela diri dalam rangka menyebarluaskan agama Islam.

2. Cis, berupa tombak bermata dua atau dwisula yang berfungsi sebagai senjata pelindung dan kelengkapan dalam berdakwah atau berkhutbah dalam rangka menyebarluaskan ajaran agama Islam.
3. Keris Komando, senjata yang digunakan oleh Raja Panjalu sebagai penanda kedudukan bahwa ia seorang Raja Panjalu.

4. Keris, sebagai pegangan para Bupati Panjalu.

5. Pancaworo, digunakan sebagai senjata perang pada zaman dahulu.

6. Bangreng, digunakan sebagai senjata perang pada zaman dahulu.

7. Gong kecil, digunakan sebagai alat untuk mengumpulkan rakyat pada zaman dahulu.

8. Kujang, senjata perang khas Sunda peninggalan seorang petapa sakti bernama Pendita Gunawisesa Wiku Trenggana (Aki Garahang) yang diturunkan kepada para Raja Panjalu.

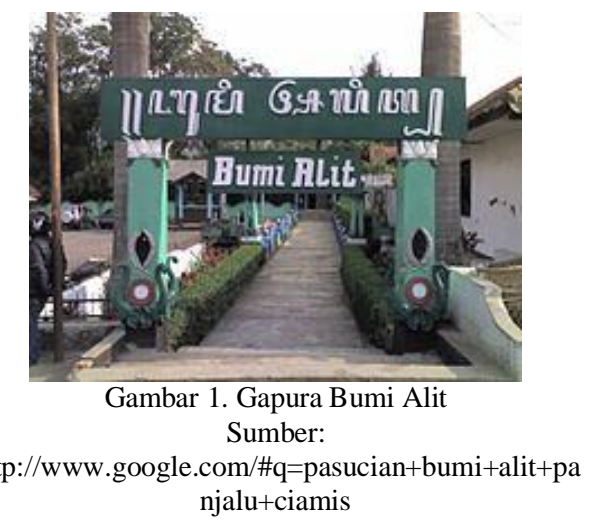

\section{Sejarah Bumi Alit}

Pada masa pemerintahan Raden Tumenggung Wirapraja bangunan Bumi Alit dipindahkan dari Dayeuh Nagasari, Ciomas ke Dayeuh Panjalu seiring dengan perpindahan kediaman Bupati Tumenggung Wirapraja ke Dayeuh Panjalu. Pasucian Bumi Alit dewasa ini terletak di Kebon Alas, Alun-alun Panjalu.

Pada awalnya Bumi Alit berupa taman berlumut yang dibatasi dengan batubatu besar serta dikelilingi dengan pohon Waregu. Bangunan Bumi Alit berbentuk mirip lumbung padi tradisional masyarakat Sunda, berupa rumah panggung dengan kaki-kaki yang tinggi, rangkanya terbuat dari bambu dan kayu berukir dengan 
dinding terbuat dari bilik bambu sedangkan atapnya berbentuk seperti pelana terbuat dari ijuk.

Ketika di Jawa Barat terjadi pengungsian akibat pendudukan tentara Jepang (1942-1945) benda-benda pusaka yang tersimpan di Pasucian Bumi Alit itu diselamatkan ke kediaman sesepuh tertua keluarga Panjalu yaitu Raden Hanafi Argadipradja (1901-1973), cucu Raden Demang Aldakusumah di Kebon Alas, Panjalu.

Begitu pula ketika di wilayah Jawa Barat berkecamuk pemberontakan DI/TII (Darul Islam/Tentara Islam Indonesia) pimpinan S.M. Kartosuwiryo (1949-1962) yang marak dengan perampokan, pembantaian dan pembakaran rumah penduduk. Para pemberontak DI/TII itu sempat merampas benda-benda pusaka kerajaan Panjalu dari Bumi Alit. Pusakapusaka itu kemudian baru ditemukan kembali oleh aparat TNI di hutan Gunung Sawal lalu diserahkan kepada Raden Hanafi Argadipradja, kecuali pusaka Cis sampai sekarang tidak diketahui keberadaannya.

Pada tahun 1955, Bumi Alit dipugar oleh warga dan sesepuh Panjalu yang bernama R.H. Sewaka (M. Sewaka) mantan Gubernur Jawa Barat (19471948,1950-1952). Hasil pemugaran itu menjadikan bentuk bangunan Bumi Alit yang sekarang, berupa campuran bentuk masjid zaman dahulu dengan bentuk modern, beratap susun tiga. Pada pintu masuk Museum Bumi Alit terdapat patung ular bermahkota dan di pintu gerbangnya terdapat patung kepala gajah. Hingga kini, pemeliharaan Museum Bumi Alit dilakukan oleh Pemerintah Desa Panjalu yang terhimpun dalam 'Wargi Panjalu' di bawah pengawasan Dinas Pariwisata dan Budaya Kabupaten Ciamis.

Daftar Para Batara, Raja, Bupati dan Demang Panjalu beserta Pusara/Petilasannya:

1. Batara Tesnajati di Karantenan Gunung Sawal.
2. Batara Layah di Karantenan Gunung Sawal.

3. Batara Karimun Putih di Pasir Kaputihan Gunung Sawal.

4. Prabu Sanghyang Rangga Gumilang atau Sanghyang Rangga Sakti di Cipanjalu, Desa Maparah, Panjalu.

5. Prabu Sanghyang Lembu Sampulur I di Cipanjalu, Desa Maparah, Panjalu.

6. Prabu Sanghyang Cakradewa di Cipanjalu, Desa Maparah, Panjalu.

7. Prabu Sanghyang Lembu Sampulur II di Cimalaka Gunung Tampomas, Sumedang.

8. Prabu Sanghyang Borosngora (adik Sanghyang Lembu Sampulur II) di Jampang Manggung, Sukabumi.

Prabu Rahyang Kuning di Kapunduhan Cibungur, Desa Kertamandala Panjalu.

9. Prabu Rahyang Kancana (adik Prabu Rahyang Kuning) di Nusa Larang, Situ Lengkong Panjalu.

10. Prabu Rahyang Kuluk Kukunangteko di Cilanglung Desa Simpar, Panjalu.

11. Prabu Rahyang Kanjut Kadali Kancana di Sareupeun, Desa Hujungtiwu, Panjalu.

12. Prabu Rahyang Kadacayut Martabaya di Hujung Winangun, Situ Lengkong Panjalu.

13. Prabu Rahyang Kunang Natabaya di Ciramping, Desa Simpar, Panjalu.

14. Raden Arya Sumalah di Buninagara, Desa Simpar, Panjalu.

15. Pangeran Arya Sacanata (adik R. Arya Sumalah) di Nombo Dayeuhluhur, Kabupaten Cilacap Jawa Tengah.

16. Raden Arya Wirabaya (anak R. Arya Sumalah) di Cilamping, Panjalu.

17. Raden Tumenggung Wirapraja (anak R. Arya Wirabaya) di Kebon Alas Warudoyong, Panumbangan Ciamis.

18. Raden Tumenggung Cakranagara I (anak R. Arya Wiradipa bin Pangeran Arya Sacanata) di Cinagara, Panjalu.

19. Raden Tumenggung Cakranagara II di Puspaligar, Panjalu.

20. Raden Tumenggung Cakranagara III di Nusa Larang, Situ Lengkong Panjalu. 
21. Raden Demang Sumawijaya di Nusa Larang, Situ Lengkong Panjalu.

Setiap tahun pada bulan Maulud, lebih tepatnya pada hari-hari yang ganjil di akhir bulan Mulud pada hari Senin atau Kamis selalu diadakan upacara sakral yaitu Nyangku atau Nyaangan Laku (menerangi tingkah laku). Acara seperti ini hampir sama dengan di Yogyakarta yaitu Sekaten dan di Cirebon, Panjang Jimat. Nyangku diambil dari kata "yanku" dari bahasa Arab yang berarti "membersihkan", artinya, Nyangku adalah membersihkan benda pusaka hanyalah sebagai simbol. Tradisi Nyangku bukan untuk kegiatan musyrik atau menyimpang, tetapi membersihkan diri dari dosa setahun lalu dan memperbaikinya di tahun yang akan datang.

\section{Nyangku}

Nyangku adalah suatu rangkaian prosesi adat penjamasan (penyucian) benda-benda pusaka peninggalan Prabu Sanghyang Borosngora dan para Raja serta Bupati Panjalu penerusnya yang tersimpan di Pasucian Bumi Alit. Istilah Nyangku berasal dari kata bahasa Arab "yanko" yang artinya membersihkan, mungkin karena kesalahan pengucapan lidah orang Sunda sehingga entah sejak kapan kata yanko berubah menjadi nyangku. Upacara Nyangku ini dilak-sanakan pada Hari Senin atau Kamis terakhir Bulan Maulud (Rabiul Awal).

Dalam rangka mempersiapkan bahan-bahan untuk pelaksanaan upacara Nyangku ini pada zaman dahulu biasanya semua keluarga keturunan Panjalu menyediakan beras merah yang harus dikupas dengan tangan, bukan ditumbuk sebagaimana biasa. Beras merah ini akan digunakan untuk membuat tumpeng dan sasajen (sesaji). Pelaksanaan menguliti gabah merah dimulai sejak tanggal 1 Mulud sampai dengan satu hari sebelum pelaksanaan Nyangku.

Disamping itu, semua warga keturunan Panjalu melakukan ziarah ke makam Raja-raja Panjalu dan bupati-bupati penerusnya terutama makam Prabu
Rahyang Kancana di Nusa Larang Situ Lengkong. Kemudian Kuncen (juru Kunci) Bumi Alit atau beberapa petugas yang ditunjuk panitia pelaksanaan Nyangku melakukan pengambilan air suci untuk membersihkan benda-benda pusaka yang berasal dari sembilan sumber mata air, yaitu:

1. Sumber air Situ Lengkong

2. Sumber air Karantenan Gunung Sawal

3. Sumber air Kapunduhan (makam Pra-

bu Rahyang Kuning)

4. Sumber air Cipanjalu

5. Sumber air Kubang Kelong

6. Sumber air Pasanggrahan

7. Sumber air Bongbang Kancana

8. Sumber air Gunung Bitung

9. Sumber air Ciomas

Bahan-bahan lain yang diperlukan dalam pelaksanan upacara Nyangku adalah tujuh macam sesaji termasuk umbiumbian, yaitu:

1. Tumpeng nasi merah

2. Tumpeng nasi kuning

3, Ayam panggang

4. Ikan dari Situ Lengkong

5. Sayur daun kelor

6. Telur ayam kampung

7. Umbi-umbian

Selanjutnya disertakan pula tujuh macam minuman, yaitu:

1. Kopi pahit

2. Kopi manis

3. Air putih

4. Air teh

5. Air Mawar

6. Air Bajigur

7. Rujak Pisang

Kelengkapan prosesi adat lainnya adalah sembilan payung dan kesenian gembyung untuk mengiringi jalannya upacara. Pada malam harinya sebelum upacara Nyangku, dilaksanakanlah acara Muludan peringatan hari kelahiran Nabi Muhammad SAW yang dihadiri oleh para sesepuh Panjalu serta segenap masyarakat yang datang dari berbagai pelosok sehingga suasana malam itu benar-benar meriah, apalagi biasanya di alun-alun 
Panjalu juga diselenggarakan pasar malam yang semarak.

Keesokan paginya dengan berpakaian adat kerajaan para sesepuh Panjalu berjalan beriringan menuju Bumi Alit tempat benda-benda pusaka disimpan. Kemudian dibacakan puji-pujian dan shalawat Nabi Muhammad SAW. Selanjutnya benda-benda pusaka yang telah dibalut kain putih mulai disiapkan untuk diarak menuju tempat penjamasan. Perjalanannya didiringi dengan irama gembyung (rebana) dan pembacaan Shalawat Nabi.

Setibanya di Situ Lengkong, dengan menggunakan perahu rombongan pembawa benda-benda pusaka itu menyeberang menuju Nusa Larang dengan dikawal oleh dua puluh perahu lainnya. Pusaka-pusaka kemudian diarak lagi menuju bangunan kecil yang ada di Nusa Larang. Benda-benda pusaka itu kemudian diletakkan di atas alas kasur yang khusus disediakan untuk upacara Nyangku ini. Selanjutnya benda-benda pusaka satu per satu mulai dibuka dari kain putih pembungkusnya.

Setelah itu benda-benda pusaka segera dibersihkan dengan tujuh sumber mata air dan jeruk nipis, dimulai dengan pedang pusaka Prabu Sanghyang Borosngora dan dilanjutkan dengan pusaka-pusaka yang lain.Tahap akhir, setelah benda-benda pusaka itu selesai dicuci lalu diolesi dengan minyak kelapa yang dibuat khusus untuk keperluan upacara ini, kemudian dibungkus kembali dengan cara melilitkan janur lalu dibungkus lagi dengan tujuh lapis kain putih dan diikat dengan memakai tali dari benang boeh. Setelah itu baru kemudian dikeringkan dengan asap kemenyan lalu diarak untuk disimpan kembali di Pasucian Bumi Alit.

Upacara adat Nyangku ini mirip dengan upacara Sekaten di Yogyakarta juga Panjang Jimat di Cirebon, hanya saja selain untuk memperingati hari kelahiran Nabi Muhammad SAW, acara Nyangku juga dimaksudkan untuk mengenang jasa
Prabu Sanghyang Borosngora yang telah menyampaikan ajaran Islam kepada rakyat dan keturunannya.Tradisi Nyangku ini konon telah dilaksanakan sejak zaman pemerintahan Prabu Sanghyang Borosngora, pada waktu itu, Sang Prabu menjadikan prosesi adat ini sebagai salah satu media syiar Islam bagi rakyat Panjalu dan sekitarnya.

\section{Tabu/ Pantangan}

Dalam Kamus Umum Bahasa Indonesia (1982:209-988) pantangan diartikan sebagai hal yang terlarang menurut adat atau kepercayaan, sedangkan tabu ialah yang dilarang atau dianggap suci (tidak boleh disentuh, diucapkan, dan sebagainya): pantangan; larangan. Dalam kamus tersebut pantangan diartikan sebagai larangan yang bila dilanggar akan menimbulkan hukuman dari alam gaib, sedangkan yang dimaksud dengan tabu ialah sesuatu larangan atau haram untuk dikerjakan oleh umum, karena pelanggaran terhadapnya akan mengakibatkan malapetaka atau menyebabkan pengaruh jelek.

Dalam upacara Nyangku dikenakan dua pantangan, yaitu berkenaan dengan waktu pelaksanaan upacara serta manusia sebagai pelakunya. Yang berkenaan dengan waktu ialah tabu melaksanakan upacara Nyangku di luar hari dan bulan yang sudah diamanatkan oleh para leluhur Panjalu. Adapun hari yang sudah diamanatkan yaitu hari Senin atau Kamis dan bulan Maulud. Jika pantangan ini dilanggar akan mengakibatkan malapetaka, sedangkan yang berkenaan dengan pelaku ialah tabu atau pantang bagi kaum ibu maupun remaja putri yang sedang datang bulan terlibat dalam pelaksanaan upacara, karena pada saat-saat tersebut mereka sedang dalam keadaan kotor atau tidak suci.

\section{M akna yang Terkandung dalam U pacara}

Manusia sebagai makhluk yang berbudaya dalam hidupnya selalu berhubungan dengan simbol-simbol. Dapat 
dikatakan bahwa simbol merupakan bagian integral dari hidup manusia. Oleh karena itu dengan begitu eratnya kebudayaan manusia dengan simbol, maka manusia pun dapat pula disebut makhluk bersimbol. Dengan melalui simbol kita dapat membaca dan menemukan nilai-nilai sebagai ekspresi kehidupan manusia. Dengan demikian, simbol dapat digunakan untuk memahami fenomena-fenomena seperti dalam berbahasa atau berkomunikasi, religi, kesenian, sejarah, ilmu pengetahuan, atau teknologi. Penggunaan simbol-simbol dalam kebudayaan adalah universal dan penting peranannya. Dengan menggunakan simbolsimbol yang dapat digunakan dengan katakata, gerak tubuh, dan upacara-upacara dapat dipertahankan keadaan yang baik dari masyarakat pendukung kebudayaan tersebut dalam segala kebutuhan (Nina Isniawati, 1988:20).

Nyangku merupakan suatu tradisi upacara yang dilaksanakan oleh masyarakat Desa Panjalu Kabupaten Ciamis, Provinsi Jawa Barat, tentunya mengandung pula makna-makna dalam serangkaian aktivitas dan perlengkapannya, meskipun tidak secara keseluruhan. Dengan kata lain dalam upacara Nyangku terdapat simbol-simbol yang makna-maknanya dapat menggambarkan kehidupan masyarakat pendukungnya. Adapun makna yang terkandung di dalam simbol-simbol upacara Nyangku adalah sebagai berikut :

1. Nyangku merupakan lambang pembersihan yang diperagakan melalui kegiatan membersihkan benda-benda pusaka keturunan leluhur Panjalu dan lambang hubungan emosional antarsesama turunan Panjalu, hubungan antar-manusia serta kesadaran sesama turunan Nabi Adam a.s. Hakikatnya pembersihan itu harus senantiasa dilakukan manusia baik untuk dirinya maupun lingkungan sebagai makhluk Allah Yang Maha Suci.

2. Cis, Pedang dan Bareng (gong kecil), melambangkan syiar Islam, dalam arti setiapraja/penguasa Panjalu harus menjadi ulama dan penyiar agama Islam. Pedang melambangkan perjuangan dalam mempertahankan syiar agama Islam, sedangkan Bareng (gong kecil) melambangkan nilai musyawarah.

3. Berapa jenis warna payung: Payung Tunggal berwarna kuning, melambangkan pengakuan manusia terhadap Kemahaesaan Tuhan. Payung susun dua berwarna hijau, melambangkan bahwa manusia dalam hidupnya di dunia menuju akhirat harus dipayungi oleh petunjuk dari Allah SWT dengan berpedoman kepada Rasulullah Muhammad Saw. Payung susun tiga dengan warna putih, melambangkan bahwa manusia dituntut berakhlak mulia Akhlaqul Karimah, seperti dalam berucap, berperilaku, memilih yang halal dan menggunakan kebenaran atau kesucian (warna putih) dalam kebijaksanaannya.

4. Sembilan kele melambangkan kegiatan-kegiatan yang ada hubungannya dengan kehidupan manusia. Kele dipegang bersama juru kunci dan perempuan, kemudian air kele itu dimasukkan ke dalam gentong. Ini mengandung arti bahwa kele yang dibawa oleh wanita ialah kele sembilan (kele selapan kunci) kemudian masuk ke dalam rahim dan terjadilah kehamilan selama 9 (sembilan) bulan.

\section{Cipanjalu}

Desa Bahara yang berada di wilayah Kecamatan Panjalu Kabupaten Ciamis ini ternyata memiliki sebuah objek wisata budaya Cipanjalu yang potensial dan tak kalah menarik dibandingkan dengan objek wisata Situ Lengkong di Desa Panjalu. Keramat Cipanjalu ini merupakan tempat tileum atau ngahyang (menghilangnya) Prabu Cakradewa, ayahanda Prabu Sanghyang Borosngora yang menjadi Raja Panjalu Islam Pertama.

Potensi yang dimiliki objek wisata Cipanjalu ini antara lain hutan lindung 
yang terawat, komplek makam keramat Prabu Cakradewa, adanya sumber mata air yang berkhasiat, Ciriung Sumur Tujuh, situs-situs maupun Batu Tulis Tampian Dalem peninggalan semasa kerajaan dipimpin Prabu Cakradewa, juga telah dibuat air pancuran untuk mandi para wisatawan dan lainnya, di samping wisatawan dapat menikmati panorama alamnya yang indah. Hutan lindung yang masih terjaga keasliannya dengan aneka pepohonan langka mewarnai kawasan Cipanjalu, sehingga ketika kuncen dipegang $\mathrm{H}$. Ayok Sukaryo, beliau menerima penghargaan Kalpataru tahun 2007 sebagai penyelamat hutan.

Sejarah singkat mengenai keberadaan Cipanjalu yang menjadi istana Prabu Cakradewa hingga 'ngahyang' menghilang. Kerajaan Panjalu yang juga dikenal sebagai Kerajaan Soko Galuh Panjalu didirikan oleh seorang puteri raja keturunan Raja Galuh yang bernama Ratu Permana Dewi bergelar Ratu Galuh Cipta Permana Dewa Nyakrawati Ing Nusa Jawa. Ratu Permana Dewi diperistri oleh Prabu Rangga Gumilang, putera Prabu Batara Tesnajati, yakni Raja Panjalu dari Karantenan Gunung Syawal. Beliau kemudian memindahkan keratonnya ke Dayeuh Luhur Panjalu dan kemudian meletakkan dasar-dasar "Ajaran Karahayuan", yang merupakan pedoman hidup masyarakat dan Negara (falsafah kerajaan). Kemudian peletakan Ajaran Karahayuan tersebut dikukuhkan oleh puteranya bernama Prabu Lembur Sampulur I yang dikenal sebagai "Raja Panjalu Leluhur"

Pemegang tahta Kerajaan Panjalu diteruskan oleh puteranya, yakni Prabu Cakradewa, seorang raja arif bijaksana serta memiliki kemampuan mambaca tanda-tanda zaman (weruh sadurung winarah, waspada permana tingal). Prabu Cakradewa sangat teguh melaksanakan Ajaran Karahayuan yang diwariskan nenek-kakeknya, Ratu Permana Dewi dan Prabu Rangga Gumilang. Prabu Sanghyang Cakradewa yang juga dikenal sebagai raja linuhung (berilmu tinggi dan berwawasan luas) dan pinandita (bersifat wiku) serta memegang teguh Ajaran Karahayuan mendambakan pewaris tahta kerajaannya dipegang oleh orang yang memiliki ilmu dan kemampuan yang berguna bagi generasi penerusnya. Prabu Cakradewa memiliki putera 6 orang, yakni Prabu Lembur Sampulur II, Sanghyang Prabu Borosngora, Panjibarani, Mamprang Kancana Atas Wayang, Anggarunting dan Pundut Agung. Prabu Borosngora adalah salah satu putranya yang dianggap memiliki kepribadian yang menonjol sehingga layak menjadi pewaris tahta Kerajaan Panjalu.

\section{Makam Keramat Kiai haji Eyang Penghulu G usti}

Ciomas adalah nama desa di kaki Gunung Syawal, Panjalu, Ciamis, Jawa Barat. Di desa ini tergambar kehidupan khas masyarakat Tatar Sunda. Dan seperti desa agraris lainnya, penduduk Desa Ciomas juga menggantungkan hidupnya kepada alam. Ketaatan dan kearifan terhadap alam inilah yang kemudian membuat Ciomas menjadi daerah harmonis dan damai.

Kearifan warga Ciomas terhadap alam tak lepas dari keberadaan hutan yang berada persis di tengah-tengah desa. Hutan seluas 35 hektar ini disebut hutan Sukarame dan dianggap keramat oleh warga. Aturan-aturan tidak tertulis dalam adat masyarakat, membuat hutan ini tetap lestari. Kepatuhan terhadap aturan inilah yang membuat hutan keramat ini masih lestari. Bahkan pemerintah sendiri pernah menganugerahi penghargaan Kalpataru bagi masyarakat Ciomas karena kepeduliannya dalam melestarikan hutan.

Kepercayaan warga terhadap hutan keramat terkait dengan keberadaan makam Kiai Haji Eyang Penghulu Gusti, yang terletak di tengah hutan Sukarame. Di sekitar makam ini pulalah upacara Nyepuh setiap tahun digelar. Menurut sesepuh Karahayuan Pangawitan Ciomas, Ki H. Dede Sadeli Suryabinangun, Eyang 
Penghulu Gusti merupakan penyebar agama Islam di Ciomas. Penghulu Gusti pulalah yang meminta warga setempat untuk selalu memerhatikan hutan dan melestarikannya. Masyarakat di sana dilarang menebang pohon, apalagi merusaknya. Siapa yang melanggar pantangan itu, dipercaya bakal mendapatkan musibah dalam hidupnya. Karena pantangan itulah tak ada seorang pun warga di sana yang berani berbuat macam-macam di hutan ini.

\section{Mulung Pangpung}

Tradisi Nyepuh sendiri meru-pakan upacara puncak dari rangkaian tradisi lain yang berlangsung sehari sebelumnya. Antara lain tradisi mulung pangpung atau pengambilan kayu bakar dan nalekan (menanyai). Dua acara ini merupakan kegiatan dalam rangka memasak tiga nasi tumpeng untuk melengkapi upacara Nyepuh keesokan harinya. Ritual memasak nasi tumpeng ini dilakukan menggunakan kebersamaan atau gotong royong.

Ritual mulung pangpung dan nalekan ini pun sangat sarat makna. Misalnya pada prosesi mulung pangpung, pengambilan kayunya harus dari hutan. Itu pun tidak boleh sembarangan. Pangpung (kayu lempung) yang diambil harus kayu yang sudah jatuh dari pohonnya. Jadi tidak boleh kayu yang masih menempel, apalagi yang masih tumbuh. Di situlah nilai pelestarian lingkungan yang diajarkan leluhur tetap dijalankan

Selain itu, proses mulung pangpung harus didampingi kuncen hutan Sukarame, yakni Ibu Siti Mariyam. Juru kuncilah yang kemudian membuka hutan agar terbuka bagi para pencari kayu yang dilakoni para pemuda desa. Pengambilan kayu ini pun harus setelah mendapatkan izin lebih dahulu dari penguasa hutan. Dengan diiringi lantunan ayat suci Alquran dan sholawat nabi, mereka berdoa di sekitar makam. Tujuannya agar kayu-kayu yang nantinya digunakan untuk memasak dapat membawa keberkahan.
Bila menengok kenyataan saat ini, kita bisa menyaksikan hutan-hutan di nusantara rusak berat karena tebang dan dijarah. Hal itu, menurut $\mathrm{Ki} \mathrm{H}$ Dede, karena simbolisasi mulung pangpung ini tidak diamalkan dalam kehidupan. Di Ciomas, 35 ha hutan Sukarena hingga kini masih lestari karena kearifan masyarakatnya. Sehingga jangan heran pemerintah pernah memberi penghargaan Kalpataru kepada masyarakat Ciomas. Bila keperluan kayu bakar dirasa telah mencukupi, para pemuda desa yang mendapat mengambil kayu harus menunjukkan kayu-kayu tersebut pada tetua desa. Sebelum dibawa ke kampung, tetua diwajibkan memeriksa kayu-kayu itu.Bila ada rayap atau sudah rapuh, kayu itu tak boleh dibawa pulang dan harus dikembalikan lagi ke dalam hutan.

\section{Ritual Nalekan}

Setelah bahan-bahan untuk memasak tersedia. Tibalah saatnya ritual nalekan dilakukan. Nalekan adalah ritual menanyai tentang segala hal berkait pembuatan nasi tumpeng, mulai dari bahan-bahan untuk memasak, hingga prosesnya. Sesuai aturan adat, bahan-bahan membuat tumpeng harus berasal dari kebaikan dan harus halal. Bila ada yang diperoleh dari jalan tidak halal, maka harus disingkirkan. Selain itu, yang memasak tiga tumpeng ini pun harus dilakukan oleh 17 wanita yang sudah menopause.

Dapur yang akan digunakan untuk memasak makanan pun tak lepas dari pengawasan para tetua. Maklum, sejumlah persyaratan harus dipatuhi. Terutama penggunaan kayu bakar dan air. Perlu diperhatikan, air untuk memasak haruslah diambil dari mata air di gunung.

Makna pemeriksaan bahan-bahan makanan sebenarnya sesuai dengan pesan bulan suci Ramadan yang akan segera datang. Di Bulan Suci inilah, umat yang menjalankan ibadah puasa diharapkan dapat menjaga segala tingkah lakunya dari perbuatan kotor. Itu pulalah yang diharapkan dari Upacara Nyepuh. Melalui 
ritual ini, warga Ciomas disadarkan tentang arti menyucikan diri untuk menjadi manusia sempurna yang fitri (Sumber: http://www.diciamis.com/menengoktradisi-nyepuh-warga-ciomas.php diakses tanggal 23 Oktober 2014).

\section{N usa G ede atau $\mathbf{N}$ usa Larang}

Prabu Sanghyang Borosngora memindahkan kaprabon (kediaman raja) dari Dayeuhluhur ke Nusa Larang. Nusa Larang adalah sebuah pulau yang terdapat di tengah-tengah Situ Lengkong. Dinamai juga Nusa Gede karena pada zaman dulu ada juga pulau yang lebih kecil bernama Nusa Pakel (sekarang sudah tidak ada karena menyatu dengan daratan sehingga menyerupai tanjung). Untuk menyeberangi situ menuju Keraton Nusa Larang dibangun sebuah Cukang Padung (jembatan) yang dijaga oleh Gulang-gulang (penjaga gerbang) bernama Apun Otek. Sementara Nusa Pakel dijadikan Tamansari dan Hujung Winangun dibangun Kapatihan untuk Patih Sanghyang Panji Barani.

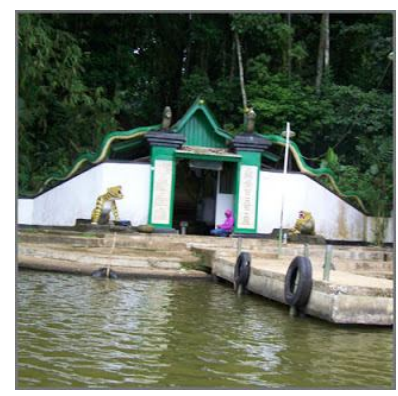

Gambar 2. Nusa Gede atau Nusa Larang Sumber:

:http://raxenasukma.blogspot.com/p/nusalarang-atau-nusa-gede-dan-asal.html

\section{Curug tujuh}

Nama lain dari Curug Cibolang adalah Curug Tujuh. Sesuai dengan namanya curug ini mempunyai 7 (tujuh) buah air terjun (curug) yang tersebar dan tidak berjauhan letaknya. Bahkan curug 4 dan 5 letaknya berdampingan hanya terpisah kurang lebih 2 meter jaraknya, sehingga dengan demikian untuk dapat menikmati keindahan dan keasrian ketujuh air terjun tersebut, adalah dengan cara mengitari bukit, menapaki jalan setapak mulai dari kaki ke puncak bukit dan kembali lagi.

Setiap curug ini memiliki nama yaitu, Curug Satu, Curug Dua, Curug Tiga, Curug Cibolang, Curug Cimantaja, Curug Cileutik dan Curug Cibuluh. Ketujuh curug ini mengalirkan air ke Sungai Cibolang dan Cimantaja.

Curug ini berada di dalam Kawasan Wana Wisata Curug Tujuh di RPH Panjalu BKPH Ciamis KPH Ciamis, dengan luas sekitar 40 ha yang dikelilingi Bukit Ciparang dan Cibolang di kaki Gunung Sawal. Kawasan ini terletak pada ketinggian antara 800-900 m dpl dengan suhu udara berkisar $17^{\circ}-18^{\circ} \mathrm{C}$.

Keberadaan Curug ini mempunyai kelebihan jika dibandingkan dengan kebanyakan air terjun lain pada umumnya, karena air terjun ini tidak pernah surut sekalipun di musim kemarau, dan air yang mengalir mengandung unsur belerang yang berkhasiat untuk penyembuhan beberapa penyakit.

Sumber air curug ini berasal air Cimantaja yang menurut mitos bahwa cimantaja yang berarti air mata raja. Konon dahulu kala ada seorang penguasa atau raja yang pada suatu waktu merasa sangat prihatin melihat keadaan di wilayahnya akibat kemarau panjang. Air tidak ada dan tanah kering kerontang, sehingga rakyatnya dirundung sengsara berkepanjangan. Sang raja kemudian bertapa untuk memohon supaya diturunkan hujan agar keadaan negerinya pulih seperti sedia kala. Namun usahanya itu tidak mendapat jawaban dari pernguasa alam. Karena tak membuahkan hasil hati sang raja merasa sedih dan kesedihannya itu membuat sang raja menangis. Saat itulah keajaiban terjadi, air mata raja yang terus turun perlahan-lahan berubah menjadi genangan air jernih dan semakin membesar sehingga membentuk aliran air yang akhirnya terpecah dan jatuh di tujuh 
buah tebing. Berkat air curug tersebut keadaan negara pun kembali sejahtera.

Setelah membeli karcis dan masuk pintu di pintu gerbang langsung akan ditemui jalan setapak berbatu yang menanjak dengan bentuk tangga. Kemiringan jalan ini mencapai hampir 45 derajat. Di ujung tangga ini akan ditemui percabangan jalan dengan papan petunjuk lokasi curug Cibolang berada. Untuk curug satu hingga lima ke arah kanan sedangkan curug enam dan tujuh ke arah kiri.

Mulai dari curug satu, dari tempat petunjuk arah, kemudian pengunjung bisa berjalan lagi sekitar 5 menit jarak yang harus ditempuh antara curug satu dengan yang lainnya, kecuali curug satu dan dua serta Curug empat, lalu Curug lima karena berdekatan lokasinya. Curug satu adalah curug yang paling besar dengan ketinggian hampir mencapai 120 meter dengan lebar sekitar 15-20 meter dan di sisi kirinya terdapat tebing datar, sedangkan lokasi curug dua berada di bawahnya.

Untuk menuju curug selanjutnya harus melewati curug satu. Konon kabarnya di salah satu curug ini ada yang yang mempunyai khasiat untuk menyembuhkan berbagai penyakit kulit. Hal tersebut karena air terjun yang mengalir berasal dari kawah Gunung Sawal yang diketahui mengandung belerang ${ }^{1}$.

\section{PEN UTUP}

Menilik tempatnya, makam yang menjadi tujuan ziarah dapat dibedakan menjadi dua, yaitu makam keluarga dan makam keramat. Pada makam keluarga, misalnya makam orang tua, orang yang berziarah umumnya bertujuan untuk mendoakan arwah yang dikubur agar mendapat keselamatan atau tempat yang baik di sisi Tuhan. Jadi, manfaatnya bukan ditujukan untuk kepentingan orang yang

\footnotetext{
${ }^{1}$ Sumber:https://sites.google.com/site/wisataair terjun/jawa-barat/curug-cibolang---ciamis
}

berziarah, melainkan untuk kebaikan roh orang yang diziarahi.

Ziarah ke makam keluarga memiliki makna kultural yang hampir sama dengan halal bihalal, di mana dalam periode tertentu, misalnya setahun sekali, orang merasa perlu menyempatkan diri pulang ke kampung halamannya untuk mengunjungi saudara-saudara dan tetangganya. Jika halal bihalal adalah silaturahmi kepada orang-orang yang masih hidup, ziarah kubur adalah silaturahmi kepada orangorang yang sudah mati. Orang yang sewaktu lebaran tidak pulang kampung untuk berhalal bihalal, ia bisa dianggap lupa asal usul. Demikian pula, orang yang dalam periode tertentu tidak melakukan ziarah, khususnya jika ia memiliki orang tua yang sudah meninggal, akan dianggap anak yang tidak berbakti.

Sementara itu, pada makam keramat, aktivitas berziarah ke sana tampaknya memiliki tujuan atau motivasi yang beragam. Hal ini mengingat bahwa orang-orang yang berziarah ke makam keramat berasal dari berbagai daerah dan kalangan serta status sosial yang bermacam-macam. Bahkan untuk makam keramat yang besar, penziarah bisa berasal dari daerah yang sangat jauh, luar pulau, sampai luar negara.

Adapun alasan yang melarbelakangi masyarakat berkunjung ke tempattempat keramat antara lain: Pertama getaran emosi keagamaan yang menuntun manusia melakukan kegiatan atau aktivitas religius. Banyak cara yang dilakukan ketika orang berziarah, antara lain melaksanakan tahlil, dzikir, dan tawasul kepada Allah SWT. Ditutup dengan doa memohon kepada Allah SWT atas berbagai keinginan, misalnya permohonan agar mendapatkan rezeki, kenaikan pangkat, mendapatkan anak yang soleh, usaha lancar, nadzar dan lain-lain. Kedua, dari pengakuan para peziarah bahwa kedatangannya ke tempat keramat merupakan salah satu upaya untuk melepaskan diri dari berbagai tekanan hidup yang tidak dapat diatasi dengan nalar 
semata. Pada umumnya mereka percaya bahwa kekuatan gaib yang dipancarkan oleh tokoh yang dikeramatkan itu bisa membantu melepaskan mereka dari kesusahan atau himpitan kehidupan.

\section{DAFTAR SUMBER}

Ahmad Mansur Suryanegara.

"Seminar Menggali Nilai-Nilai Sejarah dan Budaya Panjalu", Panitia Bersama Nyangku dan Festival, 9 Juni 2002.

Atja dan Saleh Danasasmita. 1981.

Sanghiyang Siksa Kandang Karesian. Proyek Pengembangan Permuseuman, Bandung Jawa Barat.

Ekadjati, Edi S. et al. 1983.

Wawacan Carios Munada. Jakarta: Departemen Pendidikan dan Kebudayaan Direktorat Jenderal Kebudayaan Direktorat Sejarah dan Nilai Tradisional Bagian Proyek Penelitian dan Kebudayaan Nusantara.

.1993/1994.

Empat Sastrawan Sunda Lama. Riwayat Hidup, Riwayat Kepengarangan dan Konsep Sentral Karangan Mereka. Jakarta: Departemen Pendidikan dan Kebudayaan Direktorat Sejarah dan Nilai Tradisional Proyek Penelitian dan Pengkajian Kebudayaan Nusantara.

Kamus Besar Bahasa Indonesia. 1990. Jakarta : Balai Pustaka.

Lembaga Basa \& Sastra Sunda. 1975 Kamus Umum Basa Sunda. Bandung: Tarate.

Mustapa, R. H. Hasan. 1985.

Adat Istiadat Orang Sunda. Bandung: Alumni.

Natapradja, Iwan. 2005.

Wangsit dan Falsafah Sanghyang Borosngora Syeh Panjalu. Ciamis: Yayasan Borosngora

Rusyana, Yus. 1988/1989.

Pandangan Hidup Orang Sunda (seperti Tercermin dalam Kehidupan Masyarakat Dewasa Ini) Tahap III. Bandung: Depdikbud.
Rosidi, Ajip. 1970.

Carita Mundinglaya Di Kusumah. Bandung: Proyek Penelitian Pantun.

Sutrisno, Sulastin. 1981.

Relevansi Filologi. Yogyakarta: Universitas Gajah Mada. 